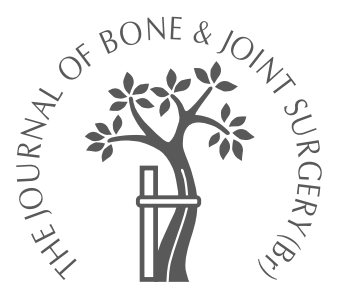
C. A. Beeton,
D. Chatfield,
R. A. Brooks,
N. Rushton

From Addenbrooke's Hospital, Cambridge, England

\footnotetext{
C. A. Beeton, PhD, Research Associate R. A. Brooks, PhD, Senior Research Associate N. Rushton, FRCS, Director Orthopaedic Research Unit, Box 180, Addenbrooke's Hospital, Hills Road, Cambridge CB2 20Q, UK.

D. Chatfield, Research Sister, RGN, BSc Hons. Dip Crit Care

Department of Anaesthesia, Box 93, Addenbrooke's Hospital, Hills Road Cambridge CB2 20Q, UK.

Correspondence should be sent to $\operatorname{Dr}$ C. A. Beeton.
}

(C)2004 British Editorial Society of Bone and Joint Surgery doi:10.1302/0301-620X.86B6. $14176 \$ 2.00$

$J$ Bone Joint Surg $[\mathrm{Br}]$ 2004;86-B:912-7.

Received 16 January 2003. Accepted after revision 25 November 2003

\title{
Circulating levels of interleukin- 6 and its soluble receptor in patients with head injury and fracture
}

There is evidence that fractures heal more rapidly in patients with head injury. We measured the circulating level of interleukin-6 (IL-6) and its soluble receptor (sIL-6R) and soluble glycoprotein 130 (sgp130) in serum from patients who had sustained a head injury with and without fracture and compared these with levels found in control subjects.

Within 12 hours of injury the serum level of IL-6 was significantly higher in patients with head injury and fracture compared with the control group. Levels of IL- 6 were also significantly higher in patients with head injury and fracture compared with fracture only. While there was no significant difference in circulating levels of sIL-6R in the initial samples they were increased one week after surgery in patients with head injury and fracture and with head injury only. In addition, reduced levels of sgp130 in patients with head injury with and without fracture indicated a possible reduction of the inhibitory effect of this protein on the activity of IL-6.

Our study suggests that IL- 6 may be involved in altered healing of a fracture after head injury.

The healing of fractures of long bones involves a complex series of cellular and biochemical events which are thought to arise primarily from the response of periosteal cells to disruption of the mechanical integrity of bone. ${ }^{1}$ While there have been several reports which indicate that both the production of callus and rates of healing of fractures are increased by concomitant head injury, ${ }^{2-4}$ the mechanisms remain unclear. Additionally, heterotopic ossification is found in patients with traumatic paraplegia. ${ }^{3-5}$ Either a neuronal or a humoral mechanism might be responsible for the connection between injury to the central nervous system and the formation of new bone at a distant site. Preliminary studies have shown that sera from patients with head injury stimulated both the proliferation of osteoblasts and the production of alkaline phosphatase in vitro. ${ }^{6,7}$ If this stimulation is being produced by the same factor or factors responsible for modified healing of the fracture it is important that they are identified.

Interleukin-6 (IL-6) is a pleiotropic cytokine expressed and secreted by cells of the osteoblastic lineage and osteoclasts, among others, in response to osteotropic hormones such as parathyroid hormone, and vitamin D and IL- $8 .{ }^{8}$ While the osteoclast is the most abundant cellular source of IL- 6 described to date, IL-6 is a fairly weak stimulator of the formation of osteoclasts in vitro. ${ }^{9,10}$ A recent IL-6 knockout model showed increased bone resorption in IL-6 deficient animals which correlated with increased numbers of osteoclasts and suggested that endogenous expression of IL-6 has significant anti-inflammatory effects in modulating the destruction of bone in vivo. ${ }^{11}$ IL-6 exerts its activity via membrane-bound receptors resulting in the homodimerisation of membrane-bound glycoprotein 130 (gp130), and intracellular signalling through tyrosine kinases and phosphorylation. ${ }^{12,13}$ IL-6 receptors are found on osteoblasts $^{14,15}$ and other cell types. A soluble form of the receptor is thought to arise through both proteolytic processing ${ }^{16}$ and differential mRNA splicing. ${ }^{17,18}$ Recent literature suggests that the important factors determining biological activity are the concentrations of IL-6/sIL-6R complexes and of free IL-6. The IL-6/sIL-6R complex is able to bind to membrane-bound gp130 and a high plasma concentration of IL-6/sIL-6R will lead to cellular activation in vivo. Free IL-6 is able to attach to cells expressing membrane IL-6R and thus yield a more restricted pattern of activation. Similar to IL-6R, differential splicing and proteolytic cleavage result in a soluble form of gp130 (sgp130) which can reduce signalling 
Table I. Details of the patients in the various groups

\begin{tabular}{|c|c|c|c|}
\hline Case & $\begin{array}{l}\text { Age } \\
\text { (yrs) }\end{array}$ & Gender & Patient details* \\
\hline \multicolumn{4}{|c|}{ Head injury and fracture } \\
\hline 1 & 54 & $\mathrm{M}$ & GCS 12, ISS 17, haemorrhage, \# skull and ribs \\
\hline 2 & 69 & M & GCS 10, ISS 10 , haemorrhage, \# ribs and pelvis \\
\hline 3 & 20 & $\mathrm{~F}$ & GCS 10, ISS 18, subdural bleeding, \# skull \\
\hline 4 & 54 & M & GCS 6, ISS 40, diffuse $\mathrm{HI}$, \# ribs, tibia, fibula and clavicle \\
\hline 5 & 19 & $\mathrm{M}$ & GCS 6, ISS 22, closed HI, \# clavicle and spine \\
\hline 6 & 26 & $\mathrm{~F}$ & GCS 3, ISS 34, diffuse $\mathrm{HI}$, \# skull and femur \\
\hline 7 & 28 & $\mathrm{M}$ & GCS 7, ISS 43, diffuse $\mathrm{HI}$ \# skull and ribs \\
\hline 8 & 19 & M & GCS 9, ISS 16, haemorrhage, \# skull \\
\hline 9 & 20 & M & $\begin{array}{l}\text { GCS 3, ISS 34, frontal contusions and haemorrhage, \# clavicle, } \\
\text { femur and metacarpals }\end{array}$ \\
\hline 10 & 58 & M & GCS 7, ISS 11, haemorrhage, \# skull and ribs \\
\hline 11 & 22 & $\mathrm{~F}$ & GCS 8, ISS 9, frontal contusions and haemorrhage, \# clavicle \\
\hline 12 & 18 & $\mathrm{M}$ & GCS 6, ISS 34, diffuse HI, \# skull, clavicle \\
\hline 13 & 47 & $\mathrm{~F}$ & GCS 7, ISS 20, diffuse HI, \# clavicle and femur \\
\hline 14 & 23 & M & GCS 6, ISS 23, assault, closed $\mathrm{HI}$, \# ribs \\
\hline 15 & 18 & $\mathrm{~F}$ & GCS 7, ISS 25, diffuse $\mathrm{HI}$ \# skull and ribs \\
\hline 16 & 23 & $\mathrm{M}$ & GCS 3, ISS 38, diffuse $\mathrm{HI}$ \# skull and ribs \\
\hline 17 & 26 & M & GCS 10, ISS 49, subdural bleeding, \# skull and femur \\
\hline 18 & 53 & $\mathrm{~F}$ & GCS 9, ISS 13, subdural bleeding, \# skull \\
\hline 19 & 21 & $\mathrm{M}$ & GCS 7, ISS 25, diffuse HI, \# skull \\
\hline 20 & 39 & M & GCS 3, ISS 25, haemorrhage, \# skull, ribs, and pelvis \\
\hline 21 & 61 & $\mathrm{M}$ & GCS 8, ISS 9, haemorrhage, \# clavicle \\
\hline \multicolumn{4}{|c|}{ Head injury only } \\
\hline 22 & 55 & $\mathrm{M}$ & GCS 7, ISS 15, unrousable because of alcohol \\
\hline 23 & 25 & M & GCS 7, ISS 11, haematoma, frontal contusions \\
\hline 24 & 36 & M & GCS 9, ISS 17, fell downstairs because of alcohol \\
\hline 25 & 57 & $\mathrm{~F}$ & GCS 3, ISS 25, haematoma \\
\hline 26 & 26 & M & GCS 7, ISS 25, unrousable because of alcohol \\
\hline 27 & 53 & $\mathrm{M}$ & GCS 8, ISS 9, unrousable because of alcohol \\
\hline 28 & 19 & $\mathrm{M}$ & GCS 6, ISS 25, haematoma \\
\hline 29 & 42 & $\mathrm{~F}$ & GCS 7, ISS 25, fell downstairs because of alcohol \\
\hline 30 & 38 & $\mathrm{M}$ & GCS 4, ISS 25, haematoma \\
\hline 31 & 68 & $\mathrm{~F}$ & GCS 8 , ISS 17, haematoma \\
\hline
\end{tabular}

* GCS, Glasgow coma score at intubation; ISS, injury severity score; HI, head injury; \#, fracture

of IL- 6 by inactivating the extracellular IL-6/sIL-6R complex. $^{12}$

We chose to measure the circulating levels of IL-6, sIL6R and sgp130 in serum because of the known involvement of IL-6 in bone turnover, its role in the pathogenesis of such disease processes in bone as Paget's disease, ${ }^{19}$ and the reported elevated level in the plasma of patients with head injury. ${ }^{20}$ Additionally, animal studies ${ }^{21-28}$ and preliminary studies in $\operatorname{man}^{20,29-31}$ have shown increased levels of IL-6 after trauma, but the possible effect on the repair of fractures and measurement of sIL-6R and sgp130 in the same patients have not been reported. To date, there have been few studies of human subjects with head injuries and none which have examined specifically IL-6, sIL-6R or sgp130 in patients with both head injuries and fractures.

\section{Patients and Methods}

Patients were selected based on the following exclusion criteria: younger than 18 years of age, over the age of 75 years, diabetic, receiving steroids or bisphosphonates and with a previous head injury or bone related pathology. Details of the patients with head injury and fracture and head injury alone are given in Table I. In addition there were 13 patients with fracture only. There were six women and seven men with a mean age of 38.7 (21 to 73 ) whose fractures involved the femur (seven), upper limb (two), tibia and fibula (one), ankle (one), arm and foot (one) and spine (one).

The Glasgow coma scale (GCS) and injury severity score (ISS) were calculated for each patient with a head injury both on arrival and at intubation. All procedures were performed under the guidelines of and following approval from the local research ethics committee. Within the first few hours of admission to hospital $20 \mathrm{ml}$ of blood were obtained from 21 patients with head injury and fracture, ten with head injury only and 13 with fracture only. Weekly blood samples were obtained from those with a head injury for the duration for their stay in hospital which varied from between one and three weeks. Blood was also taken from 13 patients attending outpatient appointments (phlebotomy controls following the same exclusion criteria); there were four women and nine men with a mean age of 34.1 years (18 to 67) and from ten apparently healthy volunteers, six of whom were women and four men with a mean age of 37.3 years (21 to 58 ). All the blood samples were allowed to clot for up to 30 minutes at room temperature 


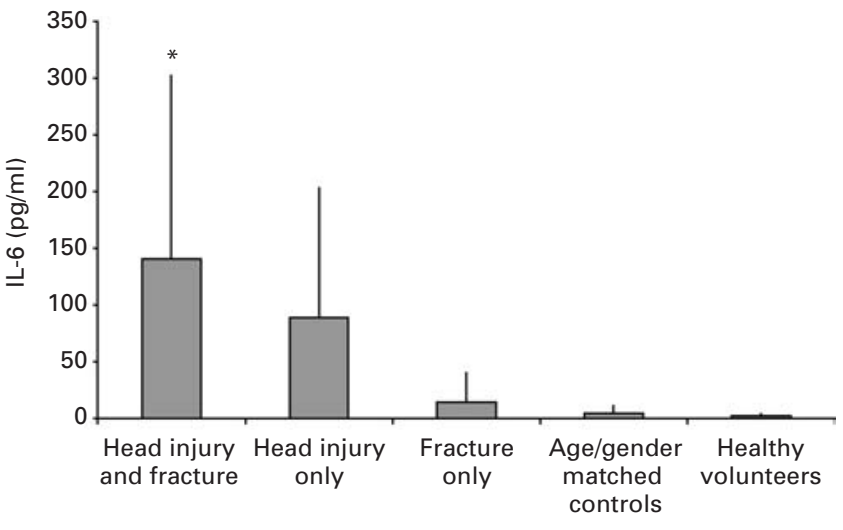

Fig. 1a

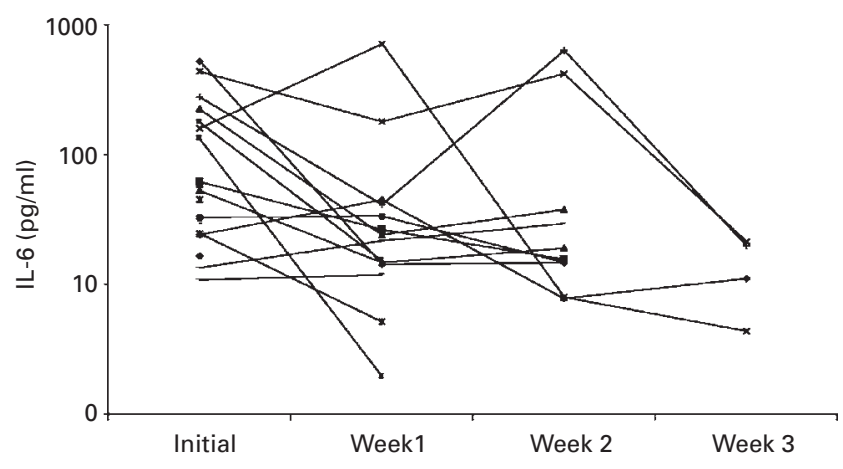

Fig. 1b

Figure 1a - Mean (SD) circulating serum levels of IL-6 obtained from patients in the various groups within hours of injury (*, significant difference compared with the phlebotomy control group, healthy volunteers and patients with fracture only). Figure $1 \mathrm{~b}-\mathrm{Changes}$ in circulating serum levels with time in patients who had sustained both a head injury and fracture.

and were spun at $1540 \mathrm{~g}$ for ten minutes. Serum was removed and stored at $-80^{\circ} \mathrm{C}$ until use.

The serum was thawed at room temperature, mixed thoroughly before use and the levels of IL-6, sIL-6R and sgp130 were measured by enzyme-linked immunosorbant assay (ELISA; R\&D Systems Europe Ltd, Abingdon, UK) following the manufacturers' instructions. The minimal detectable amounts of IL-6, sIL-6R and sgp130 were $<0.2$ $\mathrm{pg} / \mathrm{ml}, 6.5 \mathrm{pg} / \mathrm{ml}$ and $<0.05 \mathrm{ng} / \mathrm{ml}$, respectively.

Statistical analysis. Shapiro-Wilk's test of normality was performed. Data, which were not normally distributed were transformed logarithmically and retested to ensure normal distribution before analysis by univariate ANOVA. Further analysis using the Levene test showed equality of variances between groups after logarithmic transformation. Student's $t$-test with Bonferroni correction was used to identify differences between groups with significance at the 0.05 level.

\section{Results}

Age and gender had no effect on the circulating levels of IL6, sIL-6R or sgp130 and no significant difference in the levels of these factors between the phlebotomy control group and the healthy volunteers.

Levels of IL- 6 within 12 hours of admission. The circulating level of IL-6 in serum was found to be significantly higher in patients who had sustained both head injury and fracture compared with the phlebotomy control group $(\mathrm{p}=0.005)$ and the healthy volunteers $(p=0.008)$ (Fig. 1a). Several of the patients with either head injury only or fracture only showed high circulating levels of IL- 6 but the means of these groups were not significantly greater than those of the control groups. When compared with patients who had sustained fractures only, those who had a head injury with fracture had a significantly raised level of circulating IL-6 ( $p$ $=0.009$; Fig. 1a).
Changes in the level of IL-6 in serum with time. There was no significant change in the concentration of IL- 6 between the intial samples and those taken one week after injury in patients who had sustained both a head injury and fracture $(\mathrm{p}=0.348$; Fig. $1 \mathrm{~b})$. These levels did not return to that found in healthy volunteers in the time period used in our study.

Levels of soluble IL-6 receptor within $\mathbf{1 2}$ hours of admission. There were no differences between groups of patients when the mean levels of circulating sIL-6R at the initial time points were considered ( $p=0.339$; Fig. $2 \mathrm{a}$ ).

Changes in the level of sIL-6R in serum with time. The circulating level of sIL-6R in serum one week after injury was significantly higher in patients who had sustained a head injury with and without fracture compared with the initial sample ( $\mathrm{p}=0.012$ and $\mathrm{p}=0.011$, respectively; Figs $2 \mathrm{~b}$ and $2 c)$, but this was not significant after two weeks.

Levels of sgp 130 within 12 hours of admission. Levels of sgp130 were significantly lower in patients who had sustained a head injury with and without fracture compared with those who had sustained a fracture only $(\mathrm{p}<0.001$ and $p=0.026$; Fig. 3a). Patients who had suffered both a head injury and fracture had significantly lower levels of sgp130 compared with the phlebotomy control group and healthy volunteers ( $<<0.001$; Fig. 3a).

Changes in the level of sgp130 in serum with time. There was a significant increase in the level of sgp130 in patients who had sustained both a head injury and fracture after one week compared with the initial time point $(\mathrm{p}=0.022$; Fig. $3 b)$.

\section{Discussion}

Our study has shown that the circulating level of IL- 6 is significantly raised in patients who have sustained head injury and fracture compared with uninjured control subjects and that the level remained high at later time points. The serum 


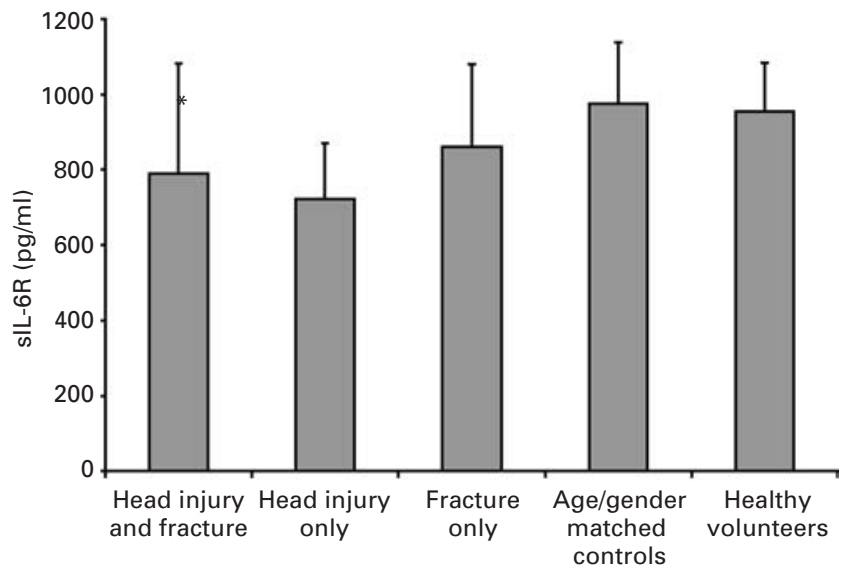

Fig. 2a

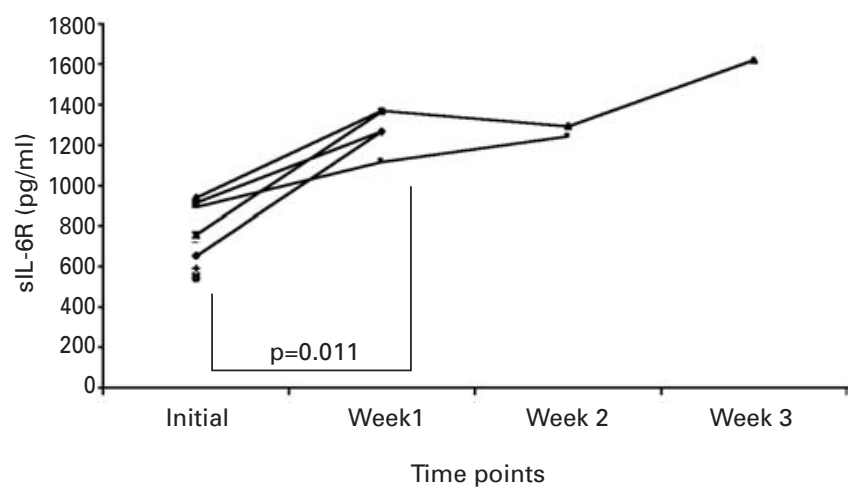

Fig. 2c

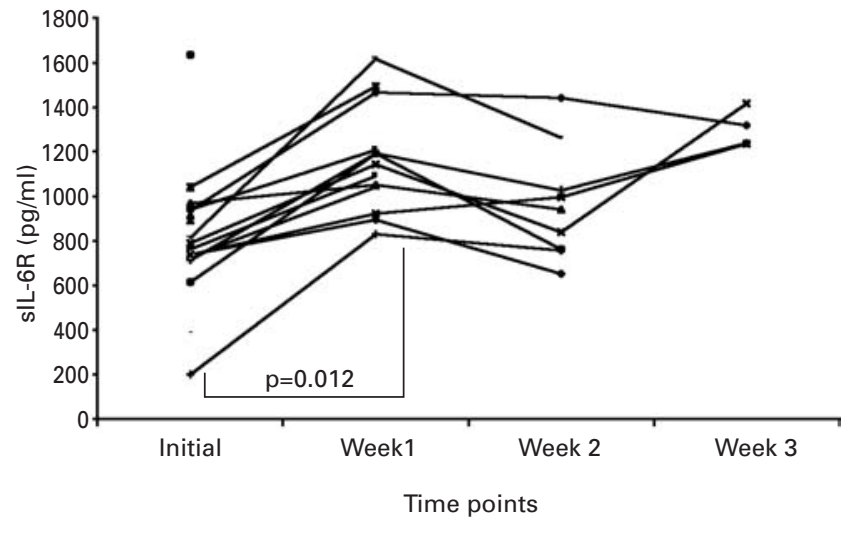

Fig. 2b

Mean (SD) circulating serum levels obtained from patients a) within hours of injury b) over a period of time in those who had sustained both a head injury and fracture and c) over a period of time in those who had had a head injury.

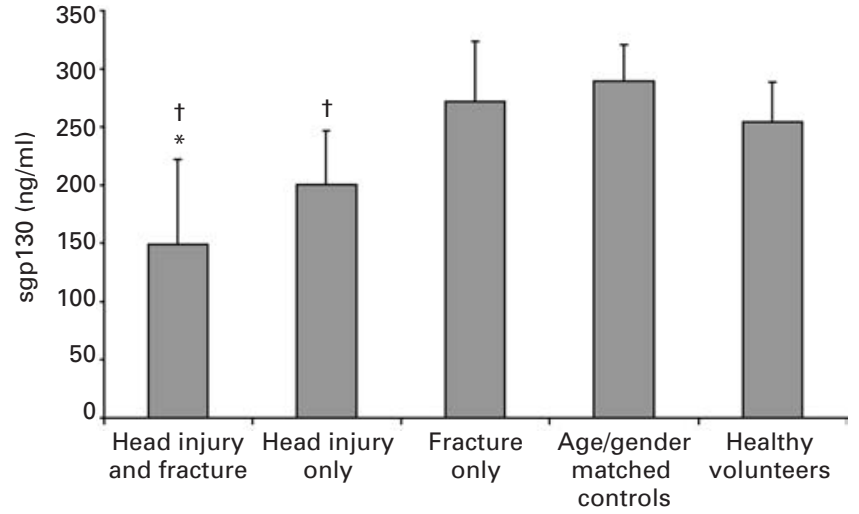

Fig. 3a

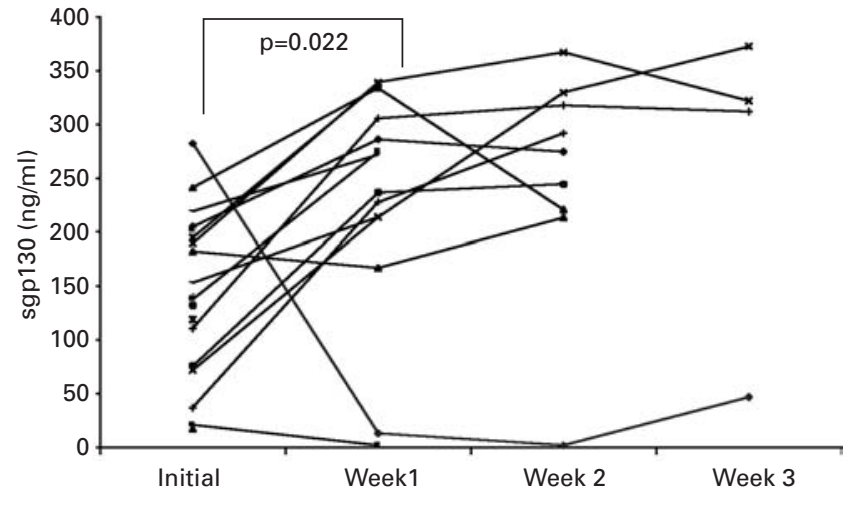

Fig. 3b

Mean (SD) circulating levels of sgp130 in a) patients within hours of injury and b) with time in patients who had had both a head injury and fracture ${ }^{*}$, significant differences compared with the phlebotomy control group and healthy volunteers; $†$ significant difference compared with patients with fracture). 
levels of sIL-6R were not significantly different between the groups of patients at the initial time point, but increased significantly after one week in those who had sustained both a head injury and fracture. Our study also showed lower levels of circulating sgp130 in patients who had sustained a head injury with and without fracture, which increased one week after the injury. We propose a mechanism based on the results of our study to explain the relationship between head injury and healing of a fracture whereby the altered levels of IL-6, sIL-6R and sgp130, observed in patients with head injury, stimulate cells within the fracture callus leading to altered repair of the fracture.

It has been reported that sIL-6R potentiates the agonistic effects of IL-6 in cell lines or gene-transfected cells. ${ }^{15,32-36}$ We suggest that while the serum levels of sIL-6R do not vary initially between our five groups of patients, it is the circulating level of IL-6 immediately after injury which may be important in modifying cell responses. Levels of IL-6 were greater in some patients with a fracture alone than in healthy individuals suggesting release after trauma. This is in agreement with previously published data. ${ }^{20-24,37,38}$ However, IL-6 is elevated to a much greater level in patients who have sustained a head injury and we postulate that this may be, in part, responsible for stimulating the early stages of the repair of a fracture within hours of trauma. In addition to this, the lower levels of sgp130 in these patients may reduce antagonistic binding to either IL-6 or IL-6/sIL-6R enhancing a possible role of IL- 6 in the repair of a fracture seen in patients with severe head injury. The resulting increased level of the circulating IL-6/sIL-R complex may be capable of stimulating cells of the mesenchymal lineage and therefore increasing the formation of osteoblastic bone.

A week following trauma, the levels of IL-6 in patients with both head injury and fracture had decreased but remained higher than in non-injured control subjects. This, in combination with increased sIL-6R, may be capable of sustaining an effect on the repair of a fracture by forming the IL-6/sIL-6R complex and maintaining agonist activity at the site of the fracture.

A number of studies have shown the circulating level of IL- 6 to be raised in a variety of conditions such as alcoholic liver disease ${ }^{39}$ and various rheumatological diseases. ${ }^{37,40}$ Hack et $\mathrm{al}^{41}$ found that increased plasma levels of IL- 6 correlated with physiological markers of sepsis, and although no patients in our study showed signs of sepsis, this potential influence cannot be eliminated. Trauma itself may also be associated with increased IL- 6 since Taniguchi et al, ${ }^{38}$ have shown that levels of plasma IL- 6 were elevated after chest and abdominal trauma. They do not report details of head injury or fractures, however, and it is therefore difficult to isolate the effects of trauma alone.

There are also conflicting reports suggesting that levels of IL-6 may correlate with the severity of injury or the clinical outcome. ${ }^{20,31,42-44}$ However, we found that the levels of IL6, sIL-6R and sgp130 did not correlate with the GCS score.
In conclusion, we have shown changes in the profiles of IL-6, sIL-6R and sgp130 and propose a mechanism by which altered repair of a fracture may occur in patients with head injury. If this finding is confirmed by further in vitro and in vivo studies, this will indicate that the activity of circulating IL-6, either alone or in combination with its soluble receptor, could stimulate the early stages of repair of a fracture. This finding would lead to studies aimed at evaluating the usefulness of administering these cytokines to promote healing of a fracture.

The authors wish to thank Mrs Joy Williamson and colleagues in the Outpatient Phlebotomy Department, Addenbrooke's Hospital, Cambridge for their cooperation in recruiting age- and sex-matched control subjects for this study, and also Dr. Jonathon Coles and Mrs Diana Day for their help in recruiting patients with head injuries. This work was supported by the AO/ASIF foundation, The Wishbone Trust and Addenbrooke's Charities Committee.

No benefits in any form have been received or will be received from a commercial party related directly or indirectly to the subject of this article.

\section{References}

1. Oni 00A. Callus formation during diaphyseal fracture repair. Orthop 1996;4:269-77.

2. Perkins R, Skirving AP. Callus formation and the rate of healing femoral fractures in patients with head injuries. J Bone Joint Surg [Br] 1987;69-B:521-4.

3. Spencer RF. The effect of head injury on fracture healing: a quantitative assessment. J Bone Joint Surg [Br] 1987;69-B:25-8.

4. Stone MH, Newman RJ, Mukherjee SK. Accelerated fracture union in association with severe head injury. J Bone Joint Surg [Br] 1987;69-B:493.

5. Smith R, Triffit JT. Bones in muscles: the problem of soft tissue ossification. Q J Med 1986;61:985-90

6. Kurer MHJ, Khokher MA, Dandona P. Sera from paraplegics with heterotopic ossification and patients with fractures and head injury stimulate human osteoblasts in vitro. J Bone Joint Surg [Br] 1991;73-B(Supp 1):59.

7. Bidner SM, Rubins JM, Desjardins JV, Zukor DJ, Goltzman D. Evidence for a humoral mechanism for enhanced osteogenesis after head injury. J Bone Joint Surg [Am] 1990;72-A:1144-9.

8. Feyen JHM, Elford P, Dipedova FG, Trechsel U. Interleukin- 6 is produced by bone and modulated by parathyroid-hormone. J Bone Miner Res 1989;4:633-8.

9. Ishimi Y, Miyuara C, Jin CH, et al. IL-6 is produced by osteoblasts and induces bone resorption. J Immunol 1990;145:3297-303.

10. Black K, Garrett IR, Mundy GR. Chinese-hamster ovarian-cells transfected with the murine interleukin-6 gene cause hypercalcemia as well as cachexia, leukocytosis and thrombocytosis in tumor-bearing nude-mice. Endocrinology 1991;128:2657-9.

11. Balto K, Sasaki H, Stashenko P. Interleukin-6 deficiency increases inflammatory bone destruction. Infect Immun 2001;69:744-50.

12. Jones SA, et al. The soluble interleukin 6 receptor: mechanisms of production and implications in disease. FASEB J 2001;15:43-58.

13. Murakami M, Hibi M, Nakagawa M, et al. Il-6-induced homodimerization of Gp130 and associated activation of a tyrosine kinase. Science 1993;260:1808-10.

14. Udagawa N, Takahashi N, Allatsu T, et al. Origin of osteoclasts: mature monocytes and macrophages are capable of differentiating into osteoclasts under a suitable microenvironment prepared by bone marrow-derived stromal cells. Proc Natl Acad Sci USA 1990;87:7260-4.

15. Taha T, Hibi M, Hirata Y, et al. Interleukin-6 triggers the association of its receptor with a possible signal transducer: Gp130. Cell 1989;58:573-81.

16. Mullberg J, Oberthur W, Lottspeich F, et al. The soluble human IL-6 receptor: mutational characterization of the proteolytic cleavage site. Immunol 1994;152: 4958-68.

17. Oh JW, Revel M, Chebath J. A soluble interleukin 6 receptor isolated from conditioned medium of human breast cancer cells is encoded by a differentially spliced mRNA. Cytokine 1996:8:401-9.

18. Horiuchi S, Koyanagi Y, Zhou Y, et al. Soluble interleukin-6 receptors released from T-cell or granulocyte/macrophage cell-lines and human peripheral-blood mononuclear-cells are generated through an alternative splicing mechanism. Eur J Immunol 1994:24:1945-8.

19. Roodman GD, Kurihara N, Ohsaki Y, et al. Interleukin-6: a potential autocrine paracrine factor in Pagets-disease of bone. J Clin Invest 1992;89:46-52.

20. McClain C, Cohen D, Phillips R, Ott L, Young B. Increased plasma and ventricular fluid interleukin-6 levels in patients with head-injury. J Lab Clin Med 1991;118: 225-31. 
21. Yan HO, Banos MA, Haregodtr P, et al. Expression of interleukin (IL)-1-beta, IL-6 and their respective receptors in the normal rat-brain and after injury. Eur Immunol 1922;22:2963-71.

22. Woodroffe MN, Sarna GS, Wadhwa M, et al. Detection of interleukin-1 and interleukin-6 in adult-rat brain, following mechanical injury, by in vivo microdialysis: evidence of a role for microglia in cytokine production. J Neuroimmuno/ 1991;33:227-36

23. Taupin V, Toulmond S, Serano A, Benavides J, Zabala F. Increase in IL-6, ILand TNF levels in rat-brain following traumatic lesion: influence of pre-traumatic and posttraumatic treatment with Ro5 4864, a peripheral-type (P-Site) Benzodiazepine Ligand. J Neuroimmuno/ 1993;42:177-75.

24. Pasquale MD, Cipolle MD, Monaco J, Simon N. Early inflammatory response correlates with the severity of injury. Crit Care Med 1996;24:1238-42.

25. Miyahara S, Kornori T, Fujiwara R, et al. Effects of repeated stress on expression of interleukin-6 (IL-6) and IL-6 receptor mRNAs in rat hypothalamus and midbrain. Life Sciences 2000;66:93-8.

26. Mack VE, McCarter MD, Naama HA, Caluano SE, Daly JM. Dominance of Thelper 2-type cytokines after severe injury. Arch Surg 1996;131:1303-8.

27. Lighthall JW, Goshgarian HG, Pinderski CR. Characterisation of axonal injury produced by controlled cortical impact. J Neurotrauma 1990;7:65-76.

28. Dixon CE, Clifton DL, Lighthall JW, Yaghmai AA, Hayes RL. A controlled cortical impact model of traumatic brain injury in the rat. J Neurosc Methods 1991;39:253-62

29. Hensler T, Saverland S, Bouillon B, et al. Association between injury pattern of patients with multiple injuries and circulating levels of soluble tumor necrosis facto receptors, interleukin-6 and interleukin-10, and polymorphonuclear neutrophi elastase. J Trauma 2002;52:962-70.

30. Amado JA, Lopez-Espadas F, Vazquez-Barquero A, et al. Blood-levels of cytokines in brain-dead patients: relationship with circulating hormones and acutephase reactants. Metabolism 1995;44:812-16.

31. Kalabalikis P, Papazogbu K, Gouriotis D, et al. Correlation between serum IL- 6 and CRP levels and severity of head injury in children. Intensive Care Med 1999;25: 288-92.

32. Yasukawa K, Saito T, Fukunaga T, et al. Purification and characterization of soluble human IL-6 receptor expressed in cho cells. J Biochem (Tokyo) 1990;108:673-6.
33. Saito T, Yasukawa K, Suzuki H. Preparation of soluble murine IL-6 receptor and antimurine IL-6 receptor antibodies. J Immunol 1991;47:168-73.

34. Mackiewicz A, Schooltink H, Heinrich PC, Rose-John S. Complex of soluble human IL-6 receptor IL-6 up-regulates expression of acute-phase proteins. J Immunol 1992;149:2021-7.

35. Gaillard JP, Bataille R, Brailly, et al. Increased and highly stable levels of functional soluble interleukin-6 receptor in sera of patients with monoclonal gammopathy Eur J Immunol 1993;23:820-4

36. Tamara T, Ukagawa N, Takahashi N, et al. Soluble interleukin-6 receptor triggers osteoclast formation by interleukin-6. Proc Nat Acad Sci USA 1993;90:11924-8.

37. Waage A, Brandtzaeg P, Halstensen A, Kierulf P, Espevik T. The complex pattern of cytokines in serum from patients with meningococcal septic shock: association between interleukin-6, interleukin-1 and fatal outcome. J Exp Med 1989:169: 333-8.

38. Taniguchi T, Koido Y, Aiboshi J, et al. The ratio of interleukin-6 to interleukin-10 correlated with severity in patients with chest and abdominal trauma. Am J Emerg Med 1999;17:548-51.

39. Felver ME, Mezey E, McGuire M, et al. Plasma tumor necrosis factor alpha predicts decreasing long-term survival in severe alcoholic hepatitis. Alcoholism-Clin Exp Research 1990;14:255-9.

40. Waage A, Halstensen A, Espevik T. Association between tumor-necrosis-factor in serum and fatal outcome in patients with meningococcal disease. Lancet 1987;1: 355-7.

41. Hack CE, De Groot ER, Felt-Bersma RJ, et al. Increased plasma-levels of interleukin-6 in sepsis. Blood 1989;74:1704-10.

42. Steffen M, PichImeier U, Zander A. Inverse correlation of interleukin-6 with solu ble interleukin-6 receptor after transplantation of bone marrow or peripheral blood stem cells. Bone Marrow Transplant 1997;20:715-20.

43. Ott L, McClain CJ, Gillespie M, Young B. Cytokines and metabolic dysfunction after severe head-injury. J Neurotrauma 1994;11:447-72.

44. Singhal A, Baker AJ, Hare GM. Association between cerebrospinal fluid interleukin-6 concentrations and outcome after severe human traumatic brain injury. J Neurotrauma 2002;19:929-37 